\title{
VYGOTSKY E A TEORIA HISTÓRICO-CULTURAL: ANÁLISE DA INCLUSÃO ESCOLAR DE DEFICIENTES INTELECTUAIS
}

\author{
VYGOTSKY AND THORY HISTORICAL AND CULTURAL: \\ ANALYSIS OF THE INCLUSION OF DISABLED SCHOOL \\ INTELLECTUAL
}

\author{
Maria do Socorro Castelo Branco M. Lima ${ }^{1}$
}

RESUMO

Analisa a inclusão escolar de deficientes intelectuais na perspectiva da Teoria Histórico- Cultural (THC). Defendida por L.S. Vygotski e seus colaboradores, esta teoria baseia-se na lei geral do desenvolvimento cultural, em dois níveis primeiramente, interpessoal e depois intrapessoal. O pensador bielo-russo, porém, acentua que somente por via das relações sociais carregadas de significações, surge o desenvolvimento das funções psicológicas superiores ou culturais mediadas pelo outro, por meio da linguagem, signo por excelência. Isto é, a essência do desenvolvimento cultural consiste na apropriação e no domínio do social. O objetivo deste artigo é abordar a deficiência intelectual à luz da perspectiva da THC. Foi utilizada, exclusivamente, a pesquisa bibliográfica, sendo os principais autores mencionados Lev Semenovitch Vygotski (1997) e Ana Maria Nurdi Padilha (2014). O texto focaliza quatro tópicos: 1- Mudança da nomenclatura de deficiência mental para deficiência intelectual; 2- Inclusão escolar/exclusão; 3- Teoria Histórico-Cultural; e 4Inclusão de deficientes intelectuais na perspectiva Histórico-Cultural, com vistas a fomentar o debate da inclusão escolar de deficientes intelectuais não apenas como produto de condições orgânicas, contudo, culturais e sociais.

Palavras-chave: Inclusão Escolar. Deficiência intelectual. Teoria HistóricoCultural.

\begin{abstract}
Analyzes the educational inclusion of the intellectually disabled in the perspective of the Historical-Cultural Theory (THC). Defended by L. S. Vygotsky and his collaborators, is based on the general law of cultural development, on two levels: - first, interpersonal and then, intrapersonal. The Belarusian thinker, however, stresses that through social relations filled with meanings, it arises the development of cultural or higher psychological functions mediated by the other, through language, sign par excellence. That is, the essence of the cultural development consist on the appropriation and in the social domain. The purpose of this article is to address intellectual disabilities in light of the THC perspective. It was utilized, exclusively, bibliographic research, the main authors mentioned were Lev Vygotsky Semenovitch (1997) and Ana Maria Nurdi Padilha (2014). The text focuses on four topics: 1- Change of nomenclature from mental disability to intellectual disabilities; 2- Educational inclusion / exclusion; 3- Historical-Cultural Theory.; and intellectual disability 4-Inclusion of
\end{abstract}


the intellectually disabled in the Historical Cultural perspective, in order to foster debate on educational inclusion of intellectually disabled ,not only as a product of organic conditions, nevertheless, cultural and social.

Keywords: Educational Inclusion. Intellectually Disabled. Historical-Cultural Theory.

\section{INTRODUÇÃO}

A análise da inclusão escolar de deficientes intelectuais na perspectiva da Teoria Histórico-Cultural se inicia com breve discussão sobre a transição da nomenclatura de deficiência mental para deficiência intelectual, uma abordagem sobre inclusão/exclusão escolar. Por fim, destacaremos a Teoria Histórico-Cultural de Lev S. Vygotsky e colaboradores ${ }^{2}$, como aporte para o debate sobre a educação inclusiva de deficientes intelectuais. Os tópicos, embora se expressem separadamente mantêm relações em suas discussões.

\section{NOMENCLATURA DEFICIÊNCIA MENTAL / NOMENCLATURA DEFICIÉNCIA INTELECTUAL}

A nomenclatura para deficiência mental surgiu na literatura em 1939, durante o Congresso de Genebra. Esta nomenclatura teve a intenção de apaziguar a negatividade imposta aos deficientes considerados um peso muito grande para a sociedade da época. Pessotti (1984) informa que, na Antiguidade Clássica, especialmente entre os gregos que cultuavam o corpo perfeito, as pessoas com deficiência eram exterminadas.

Durante o Cristianismo, a concepção preformista da deficiência, associada ao sobrenatural ou castigo divino, considerava o deficiente desprovido de razão e discernimento entre o certo e o errado, como herege, devendo ser queimado por isso.

Fonseca (1995) relata que, no século XVI, esta concepção violenta da deficiência começou a ceder espaço para uma visão orgânica. Nesta perspectiva, a ideia de que o meio social não exercia nenhuma influência sobre a pessoa com deficiência era explícita. 
De acordo com Pessoti (1984), a Modernidade alavancou novas teorias, dentre elas, a dos estudos que procuravam compreender melhor a deficiência intelectual. Nesse período, Jean Itard, médico que havia realizado trabalho com deficientes auditivos, foi desafiado pelo governo francês a educar o "menino selvagem". Jean Itard relatou suas experiências com Victor de Aveyron de forma positiva, demonstrando que pessoas com deficiência mental poderiam ser educadas. Por meio do método empirista do conhecimento, relatou que o retardo de Vitor de Aveyron não decorria de comprometimentos de origens biológicas, mas da inexistência de estímulos interpessoais, decorrentes de seu isolamento social e cultural. Jean Itard contrariou, na época, o diagnóstico do renomeado médico psiquiatra Philipe Pinel, que considerou a idiotia de Victor Aveyron condição que impossibilitava sua educação.

Conforme Mazzota (1996), apesar da valorização, do contato social, por Itard, em detrimento da visão orgânica do deficiente mental, a óptica biológica clínica da deficiência ganhou espaço, também, em outras áreas da Ciência, inclusive na Psicologia, por meio dos testes de Q.I. (Quoeficiente Intelectual), introduzidos por Alfred Binet ${ }^{3}$.

A American Association on Mental Retardation (AAMR) modificou a nomenclatura antes utilizada (retardo mental) para deficiência intelectual. Esta substituição de nomenclatura aconteceu durante a Conferência Internacional sobre Deficiência Intelectual no Canadá (2004). Essa nova terminologia tem sido adotada em vários países, inclusive no Brasil.

\footnotetext{
Incapacidade caracterizada por limitações significativas tanto no funcionamento intelectual quanto no comportamento adaptativo expresso em habilidades conceituais, sociais e práticas. Esta inabilidade se originando antes da idade dos 18 anos. (AAMR, 2006, p. 20).
}

A definição de D.I. (Deficiência Intelectual) foi ampliada pelo manual da AAMR (2010) em cinco dimensões: habilidades intelectuais, comportamento adaptativo, participação e interação social, contexto social e cultural, saúde física e mental. Antunes (2012). Esta definição mais ampla de D.I. defendida pela AAMR busca superar a estática concepção e avaliá-la, baseando-se nos apoios e suportes propostos. 
Os autores Omote (1994), Glat (2004) e Bueno (2004) defendem a tese de que a deficiência intelectual não é apenas produto de condições orgânicas, porém, sociais e culturais.

Estes autores advogam a ideia de que parâmetros para aferir a normalidade não devem ser unicamente biológicos, no entanto, também, culturais. Portanto, a deficiência deve ser compreendida como a inter-relação dos aspectos biológicos e socioculturais. (ANTUNES, 2012).

A mudança de nomenclatura, no entanto, não é suficiente para superar a ideia de inferioridade e o estigma associado ao deficiente intelectual. Somente com a mudança do olhar da sociedade para o deficiente, conudo, em busca da superação do sentimento de menos- valia posto nele, os preconceitos e estigmas poderão ser amenizados. No que se refere à escola, a mudança de nomenclatura, também, não assegura a melhoria da qualidade do atendimento educacional para estes alunos. Para que essa nomenclatura demonstre na prática sua eficiência, todavia, é necessário que traga mudanças estruturais, políticas, sociais e educacionais que privilegiem as escolas que se proponham educar deficientes intelectuais.

Deve-se salientar que a deficiência intelectual é um conceito interpretado historicamente de acordo com o dado momento social. Não obstante, deve ser refletido em conformidade com o lugar que ocupa na sociedade, em determinado contexto social.

A expectativa é de que a mudança de nomenclatura, além de ampliar o conceito de deficiência intelectual (considerando-o especificamente ao funcionamento do intelecto e não ao funcionamento da pessoa como um todo) bem como, buscando concepções socioculturais, possa contribuir para dirimir o preconceito que o deficiente intelectual carrega ao longo de sua existência.

\section{A INCLUSÃO ESCOLAR /EXCLUSÃO}

O tema da inclusão requer discussão a priori sobre exclusão. Debatê-la nos moldes da sociedade capitalista é entender que esta imprime um padrão burguês de normalidade ao empreendedor, hábil, competitivo, proativo, resiliente etc. Esta mesma pessoa a escola quer ter como aluno, com o escopo 
de prepará-lo para a vida. Aquele que não consegue se adequar a estes princípios sofre o processo de exclusão.

Evidentemente, a sociedade necessita manter vivos esses valores de ascensão social e de luta por méritos individuais, para que a pessoa seja aceita, pois, se vive em polos extremos, em uma mesma sociedade, depara a extrema riqueza e a enorme pobreza.

Assim, a exclusão explica-se, por si, por meio do próprio modelo de sociedade que a mantém baseada no labor assalariado, ou seja, com a exploração do trabalho humano. Esta sociedade de classes, propriedade privada e trabalho alienado incitam as pessoas viverem uma luta constante na busca pela sobrevivência. A manutenção deste modelo de sociedade e a sua incapacidade de constituir igualdades perpassam pela supremacia de uma classe social sobre a outra, mantendo sempre esse padrão de desigualdade.

Com efeito, mesmo que a inclusão escolar esteja proposta em leis, concretamente, se encontra bastante dificuldade em sua real efetivação. $\mathrm{Na}$ espécie humana, as pessoas possuem amplas possibilidades de serem diferentes umas das outras, constituido, dessa maneira, a própria identidade e singularidade. (GÓES, 2004)

Por conseguinte, apresenta-se, na inclusão, o grande desafio de oferecer ensino de qualidade para todos, pois, mesmo aqueles que não possuem deficiências denotam diferenças raciais, culturais, étnicas e, principalmente, econômicas (OMOTE, 2004).

$\mathrm{Na}$ perspectiva do aluno diferenciado pela deficiência, Góes (2004) salienta a escassa atenção que se concede à formação pessoal desse educando, isto é, à formação da sua identidade. Em algumas escolas, esse aluno especial é expresso como minoria. A falta de organização de atividades que propiciem o encontro com seus iguais e diferentes traz consequências que dificultam a elaboração da significação de si.

O discurso da inclusão, no entanto, com um viés na formulação da identidade desse aluno, constituindo-o como pessoa, ultrapassa os limites da organização de atividades pedagógicas. No âmbito escolar, educandos sem necessidades educacionais especiais também necessitam elaborar conceitos sobre diversidade, direitos e deveres, igualdade e desigualdade, e internalizálos. Enquanto, nesse exercício, o aluno deficiente (assim como o deficiente 
intelectual) se encontra como objeto, por outro lado, ele também necessita elaborar semelhanças e diferenças com os seus iguais e, às vezes, esse processo não é propiciado pela escola. (GÓES, 2004)

Há necessidade de se implementar metodologias diferenciadas que atendam às necessidades específicas de cada aluno, de acordo com suas limitações, referindo-se à adequação de recursos e aos procedimentos de ensino, para que a inclusão não seja efetivada apenas como concretização de matrículas de alunos com necessidades educacionais especiais em classes comuns. (GÓES, 2004)

A organização didática do ensino especial deve estar centrada nas concepções desse ensino e fazer parte do projeto geral da escola. Infelizmente, o que se observa em pesquisas realizadas com o tema e na prática, em algumas escolas, é a responsabilidade desse ensino ser delegado ao serviço de apoio ou ao próprio professor da sala, sem a participação maior da escola. (GÓES, 2004)

Padilha (2014) ensina que a concepção de aprendizado anda na contramão da adaptação, porque, ao contrário dos animais, no homem, isto ocorre pela linguagem e pelo trabalho.

Sob essa óptica, situa-se a inclusão num patamar simplista apenas de pequenos ajustamentos nas situações do cotidiano escolar, não afetando o projeto pedagógico da escola como um todo. Este educando, em várias situações escolares, torna-se alvo de exclusões dentro de sua sala de aula, quando não inserido na programação diária da classe, tornando-se subestimado e limitado a adaptações que podem não promover a aprendizagem de que o aluno especial necessita para se desenvolver.

Padilha (2014) ressalta que, quando o aluno é privado de um trabalho pedagógico que organiza o conhecimento de forma que o impulsiona da esfera real para a esfera do que está ausente, isto é, para o abstrato, não há desenvolvimento das funções psicológicas superiores. Eis uma das maiores dificuldades dos deficientes intelectuais.

Além de muitas escolas não privilegiarem, contudo, a educação especial em seu projeto pedagógico, o professor não tem tido formação suficiente, suporte humano e material necessários para realizar um trabalho pedagógico de qualidade. 
Góes (2004) destaca a ideia de que, em virtude desse panorama, muitas escolas tentam melhorar a inserção dos alunos com necessidades especiais em salas regulares. Dentre essas tentativas, encontra-se a parceria com escolas especiais, no intuito de oferecer aos alunos espaços variados de convivência e, também, auxiliar o professor em sua prática pedagógica.

Convém explicitar que esta parceria, em muitos casos, colabora com a ação de não afetar o projeto político- pedagógico da escola regular, destinando novamente aos professores inseridos no processo (educação especial e escolar regular) a responsabilidade da educação desses alunos (FERREIRA e FERREIRA, 2004).

Declaração de Salamanca, entretanto, mantém o compromisso do Brasil com a Organização das Nações Unidas (ONU), Organização das Nações Unidas para a Educação, Ciência e a Cultura (UNESCO) e ao Banco Mundial (BM), no sentido da ampliação dos indicadores de Educação Básica, relacionados ao acesso à Educação e ao papel da escola comum no atendimento às pessoas com necessidades educacionais especiais.

Autores como Ferreira e Ferreira (2004) destacam que a legislação imprime em suas leis uma escola mais aberta e capacitada para receber esses alunos com necessidades educacionais especiais, no entanto, são constatados, na maioria das escolas, choques de forças políticas e econômicas, bem como uma prática que se insere em muitas contradições.

No concerto educacional, estudiosos ainda indagam: em que local e como esses alunos com necessidades educacionais especiais podem aprender melhor, inclusive os deficientes intelectuais? Ainda, denotam questionamentos sobre qual são o propósito e a natureza da educação inclusiva em si? Advogam que este tema deveria fazer parte de uma discussão maior sobre a função da escola, não somente dos debates sobre inclusão escolar.

\section{O APORTE TEÓRICO DA TCH}

Na perspectiva da não segregação escolar de deficientes, destacase de maneira marcante um dos primeiros autores do século XX, Lev $S$. Vygotski $^{4}(2003)$ a defendê-la. O Estudioso bielo-russo apoia-se na sua teoria 
sócio-histórica, relacionando o desenvolvimento infantil e humano à sociogênese, ou seja, o desenvolvimento das estruturas do pensamento e da linguagem humana está associado à qualidade das interações sociais dos grupos nos quais estão inseridos.

Como resultado dos estudos de Vygotski (2003), é possível asseverar que o desenvolvimento das crianças com necessidades especiais, em situações de isolamento social, pode-se configurar como por demais problemáticos, principalmente com relação às estruturas do pensamento e da linguagem.

Desta forma, é relevante a convivência em grupos heterogêneos, pois enriquece as relações interpessoais mediante trocas ampliadas com pares que não se limitam às crianças iguais. A sociogênese, para Vygotski, é condição primordial para que a criança se desenvolva de forma plena; portanto, mediante a qualidade de suas interações sociais com a família, a escola, a comunidade etc. Quanto mais intensas e positivas forem as trocas psicossociais, mais enriquecido e fortalecido será o desenvolvimento infantil (VYGOTSKI 2003).

No livro Fundamentos de Defectologia (1997), o autor encontra-se com o primeiro paradoxo em relação ao desenvolvimento psicossocial das crianças deficientes, quando depara a segregação social imposta a elas. Para ele, somente em grupos heterogêneos, as crianças deficientes conseguem constituir, de maneira positiva, as estruturas, as estruturas do pensamento e da linguagem, criticando, assim, o envio deliberado para a escola especial e sua proposta pedagógica, com cunho terapêutico de afastamento da escola comum.

Na compreensão de Vygotski (1997), o prejuízo maior, relativo à segregação, se encontra na homogeneização de perfis que acontece na escola especial. Crianças com as condições intelectuais semelhantes comprometem as trocas psicossociais, enquanto aquelas com perfis diferentes possibilitam essa troca e o crescimento individual. De acordo com o modelo ontogenético vygotskiano, (a criança acrescenta novas competências àquelas em curso, por meio de apropriações semióticas, tendo o adulto ou um outro par mais desenvolvido como mediador dessa competência). Por esta razão, a crítica ao 
modelo de escolarização da educação especial que proporciona as interações psicológicas e sociais entre os iguais.

$\mathrm{Na}$ leitura de Beyer (2005) a mediação semiótica é de suma importância, pois é por meio dela que as experiências sociais e culturais são garantidas e as limitações funcionais inerentes às crianças com deficiência são compensadas.

Beyer (2005) destaca como a mediação semiótica é vista no arcabouço teórico de Vigotsky:

\begin{abstract}
Entendia que o ser humano encontrava-se acabado no que tange a linha biológica ou orgânica, particularmente o cérebro, com todas as condições estruturais para alcançar os níveis mais elevados de desempenho mental. $O$ ponto crucial e de definição seria a linha social, isto é, como, com que qualidade, com que histórico individual, ocorreria, a influência da esfera social no desenvolvimento individual (ou como o fator social interferiria no desenvolvimento ontogenético (BEYER, 2005 p.3).
\end{abstract}

Por conseguinte, o autor exprime que a Defectologia não pode se limitar ao estudo quantitativo do seu objeto, contudo, deve investigar os processos relacionados ao desenvolvimento e ao comportamento da criança, pois o que importa são as consequências da deficiência no comportamento desta criança e não a deficiência isolada. Nesta visão, a tarefa do educador das crianças deficientes é descobrir as vias peculiares pelas quais elas aprendem. Essa busca deverá ser realizada pelo meio social da própria criança.

A Defectologia, porém, como sub-ramo científico, deve dar suporte à escola para que esta se adapte aos problemas das crianças a fim de transformar a educação regular e a especial em educação social. A diferença é que, na escola social, a criança deficiente é conduzida a não se adaptar à deficiência e sim a superá-la ao máximo. A escola tradicional para deficientes preocupa-se somente com a deficiência em si, não com as metodologias e didáticas para superá-la gradualmente, "situando a deficiência como "uma coisa' estanque e não como processo". (VYGOTSKY, 1989, p.101).

$O$ estudo das leis que regem o desenvolvimento das crianças com deficiência verifica a organização do seu organismo em um conjunto que impulsiona para o equilíbrio e compensação de sua deficiência (VIGOTSKI, 1989). 
Esse processo compensador surge do caráter coletivo da conduta da criança deficiente e não do impulso interno. É no coletivo que ela encontra o material necessário à formação das funções internas para o desenvolvimento compensador, exercitando as funções psicológicas próprias e encontrando a fonte das funções psicológicas superiores.

Importantes, nesses estudos, são as investigações sobre teorias que auxiliam a compreensão de como as pessoas se desenvolvem, com ou sem deficiência, sendo fundamental a educação nesse contexto, bem como o peso dos componentes biológicos e sócio-históricos em todo o processo. As concepções de Vygotsky sobre a educação de crianças deficientes apontam para uma preocupação em livrar-se de teorias "biologizantes" sobre a deficiência e avançar no sentido de um olhar para o social. Para o autor, a educação deveria ter os mesmos procedimentos que permitissem a educação de crianças não deficientes.

Para o pesquisador, bielo-russo, não era possível separar o sujeito biológico do social. Considerando-se que o singular somente se singulariza na e pela cultura, ou seja, suas possibilidades de desenvolvimento dependem de outros membros de sua cultura, pois, conforme Vygotski (1997), o ser humano, quando nasce, possui apenas os recursos biológicos, mas é no meio social (cultura, valores, crenças) que se concretiza sua humanização, ou seja, é social e historicamente constituído.

Então, é possível compreender que o desenvolvimento infantil é iniciado em um mundo dado: Já a educação é ação humana, que ocorre em tempo e espaço específicos, principalmente entre homens em suas relações uns com os outros. Assim, a criança se desenvolve pela educação, pois "a educação não apenas influi em alguns processos de desenvolvimento, mas reestrutura as funções do comportamento em toda sua amplitude". (VYGOTSKY, 1997, p.99).

A educação, portanto, é essencial no desenvolvimento de todas as pessoas, inclusive as que possuem qualquer deficiência, assim como a deficiência intelectual. É possível entender que o aluno deve ser considerado, acima de tudo, um ser ativo capaz de pleno desenvolvimento desde que the sejam dadas as condições adequadas. Assim, a criança com deficiência possui um funcionamento diferente, de tal modo que, "não é simplesmente uma 
criança menos desenvolvida que seus coetâneos normais, mas desenvolvida de outro modo." (VYGOTSKY, 1997, p.12).

Entender a dinâmica da criança com deficiência, esclarece Vygotsky (1997), é não se limitar a estabelecer o grau de sua incapacidade, isto é, classificá-la como menos ou mais desenvolvida de acordo com o padrão de normalidade, sendo necessário considerar seus processos compensatórios, ou seja, levar em conta forças motrizes para constituir formas de enfrentar demandas do meio.

Vygotsky (1997) critica instituições especiais que procuram segregar e minimizar o círculo social. Para ele, a educação deve ser a mesma, tanto para pessoas com deficiência, quanto para as normais. Dessa forma, a educação consiste em incluir a criança com deficiência em um determinado meio social e possibilitar a compensação de sua necessidade e especificidades.

A criança com deficiência precisa de metodologias diferenciadas, para que ocorra o ensino-aprendizagem. A deficiência não deve ser concebida como um aspecto simplesmente orgânico, como um defeito. É necessário que as crianças com deficiência perpassem restrições contundentes no campo social para que se desenvolvam.

As pessoas com deficiência intelectual grave, que expressam limitações no uso da linguagem oral, no desempenho escolar, nas relações sociais, nos cuidados pessoais, entre outros, apesar das suas limitações, podem evoluir com base em tais níveis.

Portanto, Carneiro (2006) ensina:

Não se trata de comparar o desenvolvimento desses sujeitos, que possuem limites marcados biologicamente, com o de sujeitos que trazem as possibilidades orgânicas integras, sem comprometimentos, dentro do padrão considerado normal. Quero é ressaltar que é possível mudar a relação com estes sujeitos. Partindo do principio de que todo ser humano pode aprender, podemos afirmar que todos, ainda que com condições físicas, mentais, sensoriais, neurológicas ou emocionais significativamente diferentes, podem desenvolver sua inteligência. (P. 45)

A autora destaca que os sujeitos com deficiência necessitam de outra forma de aprender. É preciso maior estímulo, são necessários acesso 
aos signos e desafios que possibilitem a elaboração de funções psicológicas superiores. Assinala, no entanto, categoricamente, ser possível que aprendam.

Portanto, para que a mediação viabilize a aprendizagem, é necessário que o professor, pedagogo, fonoaudiólogo ou qualquer outro profissional tenha plena consciência de que a chave para a superação das dificuldades do deficiente está na relação social plena e não apenas no orgânico. É mediante esta relação que a insuficiência se revela e pode ser trabalhada em todas suas especificidades - assim nos ensina a Teoria Histórico- Cultural de L. S. Vygotski e seus colaboradores.

\section{A INCLUSÃO ESCOLAR DE DEFICIENTES INTELECTUAIS NA PERSPECTIVA DA TEORIA HISTÓRICO-CULTURAL}

Iniciaremos corroborando ideias já anunciadas e, portanto, evidenciando o desenvolvimento do deficiente intelectual na perspectiva do pensador bielo-russo Lev Vygotski, quando assinala que o desenvolvimento cultural dá-se, inicialmente, no plano interpessoal e, logo após, no intrapessoal; Ou seja, primeiro no interpsíquico e depois no intrapsíquico.

Esta afirmação faz-se necessária no momento em que pensamos a inclusão de pessoas deficientes intelectuais, destacando-se a função precípua do professor na mediação das funções psicológicas superiores destes deficientes.

No entendimento de Padilha (2014), é de suma importância que esse educador tenha uma concepção clara sobre a constituição do homem e, sobretudo, da pedagogia que constitua essa pessoa, ensejando o caminho para desarticular a visão biológica da deficiência e para o rompimento de pedagogias que beneficiam a sociedade burguesa. Os alunos necessitam de uma pedagogia que os ensine por via da relação com o outro, coletivamente, a se constituírem culturalmente.

Dessa maneira, esse educador poderá pensar de modo a produzir em cada pessoa o humano produzido em conjunto pelos homens, de forma intencional, direta e singular (SAVIANI, 2003). 
De acordo com Vigotsky (1995, p.147), "viver a condição humana só pode acontecer com o outro humano, no plano das relações concretas de vida social".

Portanto, a escola tem a função de desenvolver a capacidade das crianças de saírem do real, para abstrair, dando significação ao que está ausente. Partindo somente do que a criança domina, esta escola a afasta do que ela realmente precisa: apropriar-se dos signos e inserir-se culturalmente no mundo social. Somente desta forma o desenvolvimento das funções psicológicas superiores ocorre por meio da palavra, que funciona como formadora da consciência.

Trabalhos de pesquisas observam que, na prática, algumas escolas partem da premissa de que deficientes intelectuais não são capazes de abstrair, por isso, toda estrutura do seu ensino é baseada no concreto. Esta forma de conceber o deficiente intelectual configura-se numa pedagogia que impede o desenvolvimento da criança, como também reforça sua deficiência.

Primeiramente, porque a criança com atraso mental depende tanto em sua experiência das impressões concretas visuais e desenvolve tão pouco por sua própria conta o pensamento abstrato, a escola deve libertá-la do excesso do método visual-direto que serve de obstáculo ao desenvolvimento do pensamento abstrato e educar esses processos. Dito de outra forma, a escola não só deve adaptarse às insuficiências dessa criança, senão também lutar contra elas, superá-las. (VYGOTSKI, 1997, p.36).

O autor ressalta a organização didática da escola que deve se adaptar ao aluno com deficiência intelectual no sentido de promover atividades pedagógicas que estimulem a formação do pensamento abstrato (isto é, das funções superiores que, segundo Vigotsky, são as culturais). Quando a escola oferece ao aluno apenas atividades que partem do que eles já dominam, privar estas crianças de desenvolverem as funções psicológicas superiores ou culturais. Quando a criança fala apenas do seu presente, do que conhece, do que tem acesso, afasta-se do que realmente precisa: apropriar-se dos signos, desenvolvendo a capacidade de substituir o presente pelo ausente do conhecido pelo desconhecido, onde reside a maior dificuldade dos deficientes intelectuais, na abstração. O signo, na linguagem, é a única forma de inserção cultural dos deficientes intelectuais (PADILHA; BRAGA, 2012). 
Em palestra proferida na Universidade Estadual Paulista Júlio de Mesquita Filho (UNESP), durante a XII Jornada de Educação Especial, Barroco (2014) afirmou que "formar consciência é a função do educador do século XXI." A autora refere-se ao desenvolvimento das funções psicológicas superiores, destacando, principalmente, a importância dessas funções na educação do deficiente intelectual.

Martins (2013) relata a importância da escola na qualidade do desenvolvimento cultural do homem e da natureza social do psiquismo. Leontiev (2004) ressalta a força da educação no que é propriamente humano, histórico e cultural. Ele assegura que uma catástrofe em que morressem todos os adultos interromperia a história da humanidade, pois não haveria quem pudesse revelá-la às novas gerações. Isto requer pensar que, dessa forma, linguagem, leitura, escrita, operações numéricas etc. deixariam de ser transmitidas às crianças das gerações futuras.

Vigotsky enfatiza em sua obra que o bom ensino é aquele que desenvolve as funções psicológicas superiores. Trabalhos de pesquisas observam que, na prática, algumas escolas partem da premissa de que deficientes intelectuais não são capazes de abstrair, por isso, toda estrutura do seu ensino, toda sua prática pedagógica é baseada no concreto. Esta forma de conceber o deficiente intelectual configura-se numa pedagogia que impede 0 desenvolvimento da criança, como também reforça sua deficiência.

Não obstante, o professor deve observar o que o aluno consegue realizar sozinho e o momento em que necessita da ajuda do outro (colega mais experiente, professor da sala, professor de apoio), todavia, poderá observar o conhecimento da criança atual (real) e o que ela está aprendendo (desenvolvendo) e a sua possibilidade de aprendizagem futura (proximal). Nesta possibilidade de aprendizagem, Vygotski (2001) destaca a imitação como atividade não puramente mecânica, porém, faz-se necessário que a criança demonstre potencialidades intelectuais para imitação, reforçando a importância de internalização de conhecimentos não somente em crianças normais, principalmente para aquelas deficientes intelectuais.

A aprendizagem, no entanto, sucede num ritmo diferente do ensino, pois, quando se ensina, está apenas "dando início à elaboração de um 
conceito". (PADILHA, 2014, p.96). A aprendizagem acontece em momentos distintos, necessitando da lógica interna de cada um.

Outro aspecto escolar importante na perspectiva histórico-cultural e, por conseguinte, fundamental para a educação de deficientes intelectuais, é a mediação. Nessa perspectiva, quer dizer especificamente o processo de significação. Ao aprender uma palavra com ajuda do outro (interpessoal), o que levará para a esfera intrapessoal é o significado da palavra. A significação sucede ao longo da vida da pessoa. Cabe salientar que, na prática da escola, o conceito de mediação, muitas vezes, é interpretado como ajuda ao outro, causando prejuízos ao desenvolvimento das funções psicológicas superiores dos alunos.

Padilha (2014) ressalta de forma contundente, não ser qualquer mediação pedagógica a interferir positivamente nos processos de desenvolvimento. Apenas um planejamento de atividades didáticas que promovam eficiente desenvolvimento das funções psicológicas superiores de todos os alunos (beneficiando os estudantes com deficiências, inclusive intelectual), de forma que atividades de leitura e escrita, cálculo, atenção, memória, percepção, comparação, imitação etc. sejam realizadas de integradamente com alunos e professores, observando, assim, o progresso e as necessidades dos alunos, além das possibilidades de replanejamento.

Enfim, os autores destacam veementemente, a necessidade de planejamento diferenciado e apropriado das atividades para os deficientes (quer sejam intelectuais ou não). Isto requer que a escola pense o processo pedagógico do público-alvo da educação especial (alunos que possuem deficiências, transtornos globais do desenvolvimento e altas habilidades/superdotação) no âmbito do seu planejamento global.

\section{CONSIDERAÇÕES FINAIS}

À inclusão escolar é expresso um grande desafio: oferecer ensino de qualidade para todos, mesmo aos que não se enquadram no público-alvo da educação especial, denotando, porém, diferenças raciais, sociais, culturais, étnicas e econômicas. Há necessidade de oferecer metodologias diferenciadas, 
que atendam às peculiaridades de cada aluno, de acordo com suas limitações. A organização didática da educação inclusiva deverá fazer parte do projeto pedagógico geral da escola.

$\mathrm{Na}$ realidade, todavia, o que se observa em um número considerável de escolas que recebem deficientes são pequenos ajustamentos nas situações do cotidiano escolar, despreparo do professor para atuar com esse público, salas com número excessivo de alunos, desconhecimento do que sejam realmente o sentido e o ideário da educação inclusiva.

A legislação determina que as escolas sejam preparadas para receber o público- alvo da educação especial, no entanto, se verifica no cenário escolar é o choque de forças políticas e práticas educacionais contraditórias.

Estudiosos da Educação questionam cada vez mais o modelo de educação inclusiva que se quer implantar no nosso sistema educacional. Professores, gestores, e profissionais da saúde observam em seu cotidiano que o discurso se afasta a cada dia da realidade.

lacano e Mori (2004, p. 2) assinalam que a educação de estudantes deficientes intelectuais é um desafio perene, não só para docentes que trabalham na área, como também para os pais, visto que tanto as escolas regulares como seus professores se sentiam despreparados para trabalhar com esses alunos. Portanto, tinham que aceitá-los na escola sob pena de ferir a legislação vigente. Sendo assim, os pais se acham diante do fato e seus filhos podem não receber a educação adequada.

Mesmo considerando esse desse quadro, não se deve desconsiderar o trabalho que algumas escolas realizam ao empreenderem esforços na tentativa de garantir da melhor forma a aprendizagem do públicoalvo da educação especial. São, todavia, casos isolados. Pesquisas atuais (dissertações e teses) que abordam o tema não revelam, infelizmente resultados satisfatórios (OLIVEIRA, 2014).

Enfim, este artigo pretendeu analisar a educação inclusiva de deficientes intelectuais na perspectiva da Teoria Histórico-Cultural. Nos limites deste texto, abordamos o tema beneficiando-o no arcabouço de suas inúmeras dificuldades para fazê-lo ocorrer nos conformes de uma educação para todos.

Não obstante, à luz do Pensamento da Teoria Histórico-Cultural, compreendemos o desenvolvimento das funções psíquicas superiores e o 
papel da mediação escolar como fatores determinantes para o desenvolvimento cultural do deficiente intelectual. Portanto, a valorização do conhecimento acerca do desenvolvimento dessas funções psíquicas superiores, teorias pedagógicas que a embasam, organização do currículo que conforma a prática escolar, são imprescindíveis para o entendimento e organização da prática pedagógica baseada na inclusão escolar do públicoalvo da educação especial.

\section{REFERÊNCIAS}

AMERICAN ASSOCIATION ON INTELLECTUAL AND DEVELOPMENTAL ISABILITIES. Intellectual disability: definition, classification, and systems of supports. Washington, DC: AAIDD, 2010.

ANTUNES, K. C. V. Historia de Vida de Alunos com deficiência intelectual: Percurso escolar e a constituição do sujeito. 2012. Tese (Doutorado) Programa de Pós Graduação em Educação, Universidade do Estado do Rio de Janeiro, 2012.

ASSOCIAÇÃO AMERICANA DE RETARDO MENTAL - AAMR. Retardo mental - definição, classificação e sistemas de apoio (2002). 10 â edição. (tradução Magda França Lopes). Editora: ARTMED, Porto Alegre, 2006.

BEYER, H, Otto. Por que Lev Vygotsky quando se propõe uma educação inclusiva? Revista do Centro de Educação. São Paulo, CEESP №26. 2005

BUENO, J. G. Educação Especial brasileira: integração/segregação do aluno diferente. EDUC, São Paulo, 2004.

CARNEIRO, M. Silvia Cardoso. C. A deficiência mental como produção social: de Itard à abordagem histórico-cultural. In: Inclusão e escolarização: múltiplas perspectivas (Org.) Cláudio Roberto Baptista, Adriana Marcondes Machado... [et al] - Porto Alegre: Meditação, 2006.

FERREIRA, M. C. C. e FERREIRA, J. R. Sobre inclusão, políticas públicas e práticas pedagógicas. Em Góes M. C. de \& Laplane A. (Orgs). Políticas e práticas de educação inclusiva. (Pp. 21-48). Campinas: Autores Associados, 2004.

FONSECA, V. da. Educação Especial. Educação especial: programa de estimulação precoce - uma introdução às idéias de Feuerstein. Porto Alegre: Artes Médicas, 1995.

GLAT, R. A integração social dos portadores de deficiências; uma reflexão. 3 ed. Rio de Janeiro: Editora Sette Letras, 2004. 
GÓES, Maria Cecília Rafael de. Desafios da inclusão de alunos especiais: a escolarização do aprendiz e sua constituição como pessoa. In: GÓES, Maria Cecília Rafael de; LAPLANE, Adriana Lia Friszman de. (Orgs.) Políticas e Práticas de Educação Inclusiva. Campinas, SP: Autores Associados, 2004. (Coleção educação contemporânea).

IACANO,J.P; MORI,N.N.R. Deficiência mental e Terminalidade específica: novas possibilidades de inclusão ou exclusão velada?ANPED SUL, SEMINÁRIO DE PESQUISA DA REGIÃO SUL, 5 Curitiba, 2004. Anais. Curitiba: Editora Universitária Champagnat,v.1p.1-16.2004.

LEONTIEV, A. O desenvolvimento do psiquismo. São Paulo: Centauro, 2004.

MARTINS, L.M. O desenvolvimento do Psiquismo e a Educação Escolar. Contribuições à luz da psicologia histórico-cultural e da pedagogia histórico critica. Campinas: Autores Associados, 2013.

MAZZOTTA, M. J. S. Educação especial no Brasil: história e políticas públicas. São Paulo: Editora Cortez, 1996.

OLIVEIRA, A. A. S. Educação Inclusiva,Educação Especial ou Educação?Entre o Existente e o Desejado. (135-152) In: Ciência e Conhecimento em Educação Especial. OMOTE, Sadao, OLIVEIRA Anna Augusta Sampaio de, CHACON Miguel Moriel(Orgs.) São Carlos; Marquezine e Manzine; ABPEE. 2014.

OMOTE, S. Deficiência e não deficiência: recortes do mesmo tecido. In:

Revista Brasileira de Educação Especial. v. 1, n. 2, p. 65-74, 1994.

OMOTE,S. Estigma no tempo da Inclusão. Revista Brasileira de Educação

Especial: Marília v. 10, n.3,p.287-308, 2004.

PADILHA, A. M. L; BRAGA, E. F. P. Escola Básica: Condições Concretas de Existência. IN: Cadernos de Pesquisa em Educação, Vitória, v.18n.35, 2012.

Desenvolvimento Cultural e Educação Especial: Aporte Teórico para PENSAR o Desenvolvimento Psíquico do Deficiente Intelectual (89114).p.96 In: Ciência e Conhecimento em Educação Especial. OMOTE Sadao, OLIVEIRA Anna Augusta Sampaio de, CHACON Miguel Cláudio Moriel (Orgs.) São Carlos; Marquezine e Manzine; ABPEE, 2014.

PESSOTTI, I. Deficiência mental - Da superstição à ciência. São Paulo: EDUSP, 1984.

PLETSCH, M. D. Repensando a inclusão escolar de pessoas com deficiência mental: diretrizes políticas, currículo e práticas pedagógicas. 254f. Tese (Doutorado em Educação), Universidade do Estado do Rio de Janeiro, 2009. 
SAVIANI, D. Pedagogia Histórico-Crítica: primeiras aproximações. Campinas. Autores associados, 2003.

VIGOSTKI, L. S. Fundamentos da defectologia (obras completas). Tomo Cinco. Cuba: Editorial Pueblo y Educación, p.101, 1989.

VYGOTSKI, L. S. Obras Escogidas.TomollI.p.147. Madri: Visor, 1995.

Fundamentos da defectologia. Madrid: Visor, p.9-12, p.36, p.99. Obras Escogidas V, 1997.

A construção do Pensamento e da Linguagem. São Paulo: Martins Fontes, 2001.

A formação social da mente. São Paulo: Martins Fontes, 2003.

1 Doutoranda da UNESP-(Universidade Estadual Paulista "Júlio de Mesquita Filho". Professora do IFCE-(Instituto Federal de Educação Ciência e Tecnologia do Ceará.) Pedagoga. Especialista em Planejamento Educacional e Psicopedagogia. Mestra em Gestão de Negócios Turísticos.

${ }^{2}$ Os colaboradores de Vygotsky, eram os psicólogos russos Luria e Leontiev, criaram uma escola de Psicologia marxista autenticamente científica e consistentemente materialista.

${ }^{3} \mathrm{O}$ Q.I. é calculado pela fórmula: idade mental/idade cronológica $\times 100$. No Brasil, 0 cálculo do Q.I. é utilizado para classificar os alunos como imaturos ou excepcionais e encaminhá-los para as classes de educação especial (PLETSCH, 2009).

${ }^{4}$ A escrita do nome de Lev S. Vygotski, no desenvolvimento do texto, será grafado respeitando a maneira que foi escrito na obra, pois em alguns livros aparece Vygotsky.

RECEBIDO EM: outubro/2014

APROVADO EM: novembro /2014 